\title{
TRABALHANDO COM ESTATÍSTICA E DADOS PÚBLICOS NA ESCOLA: O CASO DO VAMOS CONTAR- IBGE
}

\author{
Tatiana Miranda e Renata Corrêa \\ Instituto Brasileiro de Geografia e Estatística, Brasil \\ tatianamiranda1983@gmail.com
}

O Instituto Brasileiro de Geografia e Estatística-IBGE tem como missão a produção de informações para o exercício da cidadania. Para isso, deve disseminá-las e buscar formas de ampliar seu uso pelos diferentes setores da sociedade, inclusive educadores e estudantes. Para isso, o Vamos Contar é um projeto online de comunicação do IBGE com os educadores que busca esse objetivo: propiciar que a estatística e as informações oficiais produzidas pelo IBGE façam parte da vida das escolas. Com o desafio de motivar os educadores da Educação Básica a trabalharem com a Educação Estatística, o site traz uma série de sugestões e conteúdos. No site do projeto, são propostas atividades desde a Educação Infantil até o Ensino Médio. Elas abordam desde conceitos básicos para a produção, compreensão e leitura dos dados até o o ensino da Estatística em sala de aula através das informações sobre a Sociedade Brasileira produzidas pelo IBGE.

\section{INTRODUÇÃO}

O Instituto Brasileiro de Geografia e Estatística-IBGE tem como missão a produção de informações para o exercício da cidadania. Para que essa missão se realize por completo é necessária a mais ampla disseminação possível dessas informações. Acessar essas informações públicas proporciona não só conhecimento sobre a Sociedade Brasileira em suas várias facetas. $\mathrm{O}$ conhecimento dessas informações é fator decisivo para o exercício amplo da cidadania e o monitoramento das políticas públicas, além do melhor planejamento nas mais variadas esferas.

Ao longo da história do IBGE, vem-se buscando a disseminação dessas informações para diferentes públicos e diferentes demandas, o que representa um constante desafio de comunicação numa sociedade heterogênea e um território de dimensões continentais como o Brasil.

Nas últimas décadas, com o avanço das tecnologias de informação e comunicação, os institutos de estatística vêm vivenciando um novo contexto. As divulgações que anteriormente eram feitas em publicações impressas aos poucos foram complementadas, inicialmente, pelos CD-ROMs encartados e, posteriormente, pela divulgação na Internet. A disseminação dos dados públicos vem sendo reconfigurada a partir do desenvolvimento e ampliação do uso dos computadores conectados à Internet, tendo sido consideravelmente ampliada tanto no que diz respeito ao volume de dados disponibilizados quanto à agilidade. Desde 1996, o IBGE passou a disponibilizar sua produção no seu portal, abrindo uma nova e importante porta para suas informações a todos que possuem acesso à Internet.

Além disso, nas últimas décadas, a produção do IBGE vem recebendo ampla cobertura por parte da Imprensa, o que para Fonseca (2005) representa atualmente um forte espaço de disseminação das informações produzidas pelo IBGE, através das variadas matérias em diversos veículos que diariamente são pautadas pelos resultados do Instituto. Porém, a ampla disseminação pela Internet e pelas publicações e a forte presença na mídia não garantem por si só a utilização autônoma das informações produzidas pela Instituição.

A publicação das informações no portal democratiza o acesso aos resultados. Mas estes, por sua natureza, representam um enorme volume de informações com especificidades técnicas que muitas vezes podem se impor como um desafio ao usuário menos preparado para manejálas.

A divulgação através da Imprensa tem um papel indiscutível na disseminação massiva dos resultados e da imagem institucional. Porém, conforme nos alerta Ferreira (2011), além das determinações políticas e científicas na elaboração dessas informações, elas são conformadas à linguagem jornalística para sua divulgação. A mídia vem se referenciando nas estatísticas oficiais para tratar dos mais diversos temas e tecer avaliações sobre aspectos variados da nossa

In: M.A. Sorto (Ed.), Advances in statistics education: developments, experiences and assessments. Proceedings of the Satellite conference of the International Association for Statistical Education (IASE), July 2015, Rio de Janeiro, Brazil. 
sociedade. Essa divulgação fica, dessa forma, sujeita também às implicações editoriais.

No contexto contemporâneo, em que as informações estatísticas vêm permeando o cotidiano da nossa sociedade, servindo para validar as mais variadas matérias jornalísticas, fazse ainda mais necessário a formação para a leitura e compreensão dessas informações.

"Diante desta realidade, é preciso preparar o cidadão para que compreenda o processo de geração das informações estatísticas, a fim de que seja capaz de arguir, solicitar outras informações e tomar decisões conscientes, sem se deixar levar pela "cientificidade" dos dados numéricos" (CROSSEN, 1996, p. 28 apud CARZOLA e CASTRO, 2008, p.41 )

Desse modo, a leitura crítica dos dados e a real apreensão dessa produção dependem de um esforço de formação e divulgação também para estudantes e educadores. Buscando essa penetração junto ao público escolar, o IBGE vem atuando com o projeto Vamos Contar.

\section{VAMOS CONTAR: BREVE HISTÓRICO}

Inicialmente, o Vamos Contar nasceu como uma iniciativa de divulgação das operações censitárias. No Censo 2000 e no Censo de 2010, foi feito um esforço específico para se divulgar essa pesquisa junto a alunos e educadores, através da distribuição de materiais de divulgação para todas as escolas do País. Junto a isso, foram enviadas cartilhas com sugestões para a inclusão da produção do IBGE nos trabalhos da sala de aula, de forma a trabalhar as realidades brasileiras através desses dados.

Nessas edições, o principal obstáculo encontrado foi a logística de distribuição desses materiais para todas as escolas de um país com as dimensões do Brasil, o que acarretou em alguns atrasos e extravios.

Após o Censo de 2010, o Vamos Contar tornou-se um projeto contínuo de relação do IBGE com os educadores. Desde 2012, o site está no ar (www.vamoscontar.ibge.gov.br) com sugestões de atividades, um espaço de compartilhamento de experiências (Blog do Professor) e uma área de recursos variados.

No lugar do envio de materiais de dez em dez anos, optou-se por um projeto centralizado nesse site, um projeto online buscando a inserção, em sala de aula, da estatística e das informações oficiais produzidas pelo IBGE.

Trata-se de um desafio robusto, dada a heterogeneidade das escolas brasileiras em variados aspectos, inclusive no que diz respeito à posse de computadores e ao acesso à Internet. É ainda um desafio de comunicação e motivação pois implica numa busca de contato constante com os educadores de todo o país. Para alcançar o público-alvo, foram traçadas algumas estratégias. O material publicado no site do Vamos Contar deveria ser constantemente atualizado, deveria se relacionar com as informações do IBGE e, em especial, devia ser pertinente ao conteúdo já trabalhado pelo professor ao longo do ano. Fez-se necessário amarrar o projeto e suas postagens ao contexto pedagógico brasileiro contemporâneo e seus documentos normativos.

\section{O TRABALHO PEDAGÓGICO DO VAMOS CONTAR}

No Brasil, os Parâmetros Curriculares Nacionais (1997) incluíram, como um dos tópicos a serem trabalhados no ensino de Matemática na Educação Básica, os seguintes blocos de conteúdos: Tratamento da Informação (no Ensino Fundamental) e Análise de Dados (no Ensino Médio). Esses grupos de conteúdos pretendem unir assuntos referentes a noções de Estatística, Probabilidade e Combinatória.

Entretanto, apesar da inclusão da Educação Estatística nos principais referenciais curriculares da educação nacional, o ensino da Estatística nas escolas brasileiras, assim como de grande parte das instituições escolares de outros países, ainda ocorre de maneira tímida.

Apesar da inclusão da estatística e da probabilidade no currículo de matemática de vários países, estes temas muitas vezes, são colocados no final dos programas, 
e assim, nem sempre apresentados aos alunos, por falta de tempo ou por falta de convicção de seu real interesse (LOPES, 2010: 07).

Ao mesmo tempo que essa demanda pela ampliação da Educação Estatística nas escolas seja um dos fatos que ressalte a importância do Projeto Vamos Contar, a limitada presença da Estatística na Educação Básica Brasileira é também um desafio para o projeto. Como motivar os professores a investirem seu tempo e trabalho pedagógico em uma área tão pouco disseminada nas escolas brasileiras, como é a Estatística? Na tentativa de motivar esses profissionais a trabalharem com o Letramento Estatístico e com dados estatísticos oficiais, produzidos pelo IBGE, adotamos algumas diretrizes para o nosso trabalho.

A primeira iniciativa foi com relação ao público-alvo das propostas pedagógicas expostas no site. Optamos por ampliar a área de atuação do projeto para toda a Educação Básica: desde a Educação Infantil até o Ensino Médio. Por termos como principais objetivos colaborar com a disseminação de dados do IBGE nas escolas, assim como criar formas de auxiliar no processo de formação de alunos capazes de ler e interpretar dados estatísticos, pensamos que essa formação deve ocorrer desde o início da escolaridade. Conforme afirma Carvalho (2001):

Numa sociedade onde a informação faz cada vez mais parte do dia a dia da maioria das crianças, onde grandes quantidades de dados fazem parte da realidade quotidiana das cidades ocidentais, importa que as crianças, desde logo, consigam coligir, organizar, descrever dados de forma a saberem interpretá-las e, com base nelas, tomarem decisões (CARVALHO, 2001: 29-30).

No site do Vamos Contar, existem sugestões de atividades didáticas para os alunos da Educação Infantil (especificamente na fase da Pré-Escolar que vai dos 4 aos 6 anos de idade). Essas atividades, em sua maioria, privilegiam uma didática lúdica e dinâmica com temas de interesse dessa faixa etária. Alguns exemplos de temas são: animais de estimação, brinquedos e brincadeiras e alimentação. A partir de temas próximos ao cotidiano dos alunos, elaboramos propostas que tratam de noções iniciais de conteúdos estatísticos, por exemplo: coleta de dados, legenda, contagem de elementos, habilidade de combinar, introdução à ideia de pesquisa e construção coletiva de tabela.

Se na Educação Infantil o Projeto Vamos Contar possui como foco a introdução de algumas noções de Estatística, no primeiro segmento do Ensino Fundamental $\left(1^{\circ}\right.$ ao $5^{\circ}$ ano, no qual a faixa etária média dos alunos é de 6 a 10 anos de idade) o trabalho é voltado para o Letramento Estatístico de uma maneira mais estruturada. Alguns dos objetivos do Ensino de Matemática no primeiro segmento do Ensino Fundamental, de acordo com os Parâmetros Curriculares Nacionais, dizem respeito ao tópico Tratamento da Informação, e são os seguintes:

- Identificar o uso de tabelas e gráficos para facilitar a leitura e interpretação de informações e construir formas pessoais de registro para comunicar informações coletadas.

- Recolher dados e informações, elaborar formas para organizá-los e expressá-los, interpretar dados apresentados sob forma de tabelas e gráficos e valorizar essa linguagem como forma de comunicação.

- Utilizar diferentes registros gráficos - desenhos, esquemas, escritas numéricas - como recurso para expressar ideias, ajudar a descobrir formas de resolução e comunicar estratégias e resultados.

- Identificar características de acontecimentos previsíveis ou aleatórios a partir de situações-problema, utilizando recursos estatísticos e probabilísticos (BRASIL, 1997).

As propostas didáticas do Vamos Contar para o primeiro segmento do Ensino Fundamental se baseiam nos objetivos citados acima. Um exemplo é a atividade "Um Censo na escola", que propõe a elaboração de uma pesquisa na escola para a coleta, análise e registro de 
dados sobre a clientela escolar. Outra atividade interessante é a "Caixas das Grandes Regiões Brasileiras" na qual os alunos devem coletar informações relevantes sobre aspectos que caracterizam cada uma das Grandes Regiões Brasileiras, como: fauna, flora, culinária, religiões, personagens relevantes (artistas, políticos e outros), monumentos e música. Após essa coleta, os dados são organizados em grandes caixas de papelão devidamente identificadas. Uma para cada Grane Região. Esse trabalho permite a criação de um banco de dados pelos próprios alunos para futuras consultas ao longo do ano letivo. Já na atividade "Contando as pessoas que moram em nossa casa" os alunos são estimulados a criarem gráficos simples para identificarem quais são as pessoas que moram em sua casa. Essa atividade permite, não apenas a criação de gráficos e coleta de informações, mas também a comparação entre os diferentes grupamentos familiares presentes na turma.

No segundo segmento do Ensino Fundamental $\left(6^{\circ}\right.$ ao $9^{\circ}$ ano, no qual a faixa etária média dos alunos é de 11 a 14 anos) o Vamos Contar possui como foco a maior estruturação dos conteúdos tratados nas propostas para o primeiro segmento. Também tomamos como base os objetivos do Ensino de Matemática voltados para o eixo Tratamento da Informação, contidos nos Parâmetros Curriculares Nacionais para o segundo segmento do Ensino Fundamental. Esses objetivos são:

* Coletar, organizar e analisar informações, construir e interpretar tabelas e gráficos, formular argumentos convincentes, tendo por base a análise de dados organizados em representações matemáticas diversas.

* Construir tabelas de frequência e representar graficamente dados estatísticos, utilizando diferentes recursos, bem como elaborar conclusões a partir da leitura, análise, interpretação de informações apresentadas em tabelas e gráficos. (BRASIL, 1997).

Como exemplo de atividades, para esse segmento, presentes no site do Vamos Contar podemos citar a "Construindo Gráficos- Distribuição por sexo", que propõe a elaboração de gráficos setoriais pela turma com dados sobre a distribuição da população por sexo com informações sobre o país, a unidade federativa onde moram e a turma. Outro exemplo é a proposta "A fecundidade no Brasil ao longo das décadas" que trata de conteúdos como: análise de tabelas, comparação de dados sobre fecundidade no Brasil em variadas décadas e pesquisa sobre causas e efeitos da queda das taxas de fecundidade em um país. Essa atividade, além de estimular a leitura e análise dos dados, aprofunda a percepção estatística pois, sugere o estudo sobre as causas e efeitos de determinado fato percebido graças à investigação estatística. No caso, a queda das taxas de fecundidade no Brasil.

Na última fase da Educação Básica, o Ensino Médio (com duração de três anos e atinge alunos na faixa etária, média, de 15 a 17 anos), buscamos enfocar os objetivos propostos para o Ensino de Estatística de acordo com os Parâmetros Curriculares Nacionais. Alguns pontos importantes desses objetivos são os seguintes:

Durante o ensino médio, os alunos devem aprimorar as habilidades adquiridas no ensino fundamental no que se refere à coleta, à organização e à representação de dados. Recomenda-se um trabalho com ênfase na construção e na representação de tabelas e gráficos mais elaborados, analisando sua conveniência e utilizando tecnologias, quando possível.

Durante o ensino médio, os alunos precisam adquirir entendimento sobre o propósito e a lógica das investigações estatísticas, bem como sobre o processo de investigação.

Vale destacar a necessidade de se intensificar a compreensão sobre as medidas de posição (média, moda e mediana) e as medidas de dispersão (desvio médio, variância e desvio padrão), abordadas de forma mais intuitiva no ensino fundamental (BRASIL, 2006).

Como exemplo de atividades didáticas, presentes no Vamos Contar, que colaboram para 
o alcance desses objetivos no Ensino Médio podemos citar a proposta "Origem dos emigrados" que, a partir de dados sobre emigração no Brasil, aborda conteúdos como: conceitos de frequência relativa, construção de tabela e de gráfico de setores. Outra atividade a ser citada é "Estudo e Trabalho" que, partindo da análise de dados sobre taxas de ocupação e escolaridade da população brasileira, trabalha temas como: desvio padrão, média aritmética e variância. Também procuramos eleger temas que possuem relação mais próxima com o cotidiano dos alunos, alguns exemplos de atividades desse perfil são: "Percepção da imagem corporal", "Pesquisando o uso do cigarro na escola" a "A população e a produção do lixo".

Além das propostas de atividades o site conta com vídeos, jogos on-line, recursos, como tabelas e gráficos, e com o Blog do Professor, que é um espaço de divulgação das ações pedagógicas dos professores desenvolvidas a partir de conteúdos e recursos disponíveis no portal Vamos Contar e demais conteúdos produzidos pelo IBGE. No blog os professores enviam postagens relatando os trabalhos realizados em sala de aula e seus resultados, essas mensagens são moderadas pela equipe do projeto. Temos recebido relatos de experiências bastante positivas e proveitosas. $\mathrm{O}$ mais interessante é que as postagens não se referem apenas ao trabalho com os recursos do Vamos Contar, mas de outros portais informativos do instituto: SIDRA, cidades@, países@ e IBGE. Essa experiência nos mostrou o quanto os dados e sites produzidos pelo Instituto são utilizados em sala de aula, reafirmando ainda mais a necessidade de um projeto como o Vamos Contar, que oriente pedagógica e didaticamente o trabalho docente com informações estatísticas.

\section{CONCLUSÃO}

O Brasil ainda está a caminho de uma educação de qualidade. Sabemos que a criação e viabilização de um projeto pedagógico voltado para a formação Estatística do público escolar é apenas uma colaboração para uma ação de melhoria da educação no país. Fundamentalmente objetivamos colaborar com a formação de pessoas capazes de ler e interpretar as informações produzidas pelo IBGE de maneira autônoma. Indivíduos que possam compreender de uma forma ampla sua realidade em diversos âmbitos: social, político, econômico e ambiental e, a partir da construção dessa habilidade, ter ferramentas para o acesso e efetivo exercício da cidadania. A ampliação do número de usuários do site, a boa repercussão do Blog do Professor e o crescente uso da internet por professores como fonte de pesquisa pedagógica, nos fazem pensar que o projeto Vamos Contar tem possibilidades de continuar divulgando e oferecendo recursos para o trabalho com a Estatística na Educação Básica.

\section{REFERÊNCIAS}

Brasil. (1997). Parâmetros Curriculares Nacionais: matemática. Secretaria de Educação Fundamental - Brasília: MEC/SEF.

Brasil. (2006). Ciências da natureza, matemática e suas tecnologias / Secretaria de Educação Básica. - Brasília : Ministério da Educação, Secretaria de Educação Básica.

Carvalho, C. (2001). Interação entre pares: contributos para a promoção do desenvolvimento lógico e do desempenho estatístico no $7^{\circ}$ ano de escolaridade. Departamento de Educação da Faculdade de Ciências. Universidade de Lisboa (Portugal). Tese de doutorado.

Carzola, I. M., Castro F. C. (2008). O papel da estatística na leitura do mundo: O letramento estatístico; In.UEFG Ci. Hum., Ci. Soc. Apl., Ling., Letras e Artes, Ponta Grossa, 16(1), 45-53.

Ferreira, M. B. (2011). Retratos do Brasil: o Discurso Jornalístico Sobre a Estatística Oficial do País. In: XXXIV Congresso Brasileiro de Ciências da Comunicação - INTERCOM, 34, 2011, Recife. São Paulo: Intercom. CD-ROM

Fonseca, S. M. (2005). A Notícia da Estatística: a divulgação das estatísticas do IBGE na visão dos jornalistas. In: Congresso Brasileiro de Ciências da Comunicação, 28., 2005, Rio de Janeiro. São Paulo: Intercom, CD-ROM.

Lopes, C. E. (2010). A Educação Estatística no currículo de Matemática: um ensaio teórico. In: 33 Encontro da ANPEDI. Caxambu: ANPEDI, CD ROM. 